\title{
A INVESTIGAC̣ÃO DA PRÓPRIA PRÁTICA: mobilização e apropriação de saberes profissionais em Matemática
}

\author{
Claudia Neves do Monte Freitas de Lima* ${ }^{1}$ \\ Adair Mendes Nacarato**
}

RESUMO: O presente trabalho refere-se a uma investigação da própria prática, num contexto de aulas de Matemática, com utilização de tarefas exploratório-investigativas. A pesquisa foi realizada com alunos da $1^{a}$ série do ensino médio de uma escola pública estadual, em São Bernardo do Campo/SP, em 2005. Teve-se como objetivo analisar os saberes mobilizados e apropriados pela professora-pesquisadora. Discute-se, inicialmente, essa modalidade de pesquisa e a pertinência do uso das tarefas exploratório-investigativas. A análise centra-se em episódios (audiogravados) que focalizaram a mediação/intervenção da professorapesquisadora, em contextos de trabalho dos alunos. Destaca-se a importância do outro - os alunos, os pares e os colegas pesquisadores -, que provoca estranhamentos e questionamentos e desencadeia processos reflexivos. Finalmente, analisam-se os conflitos vividos pela justaposição de papeis de professora e de pesquisadora no contexto da sala de aula.

Palavras-chave: Saberes Profissionais; Investigação da Própria Prática; Tarefas Exploratório-Investigativas.

\section{INVESTIGATING ONE'S OWN PRACTICE:}

\section{mobilization and incorporation of professional knowledges in Mathematics}

ABSTRACT: This paper refers to an investigation of a teacher's own practice, in mathematics classes, with the use of exploratory-investigative tasks. The research was carried out with high-school first graders at a public state school in São Bernardo do Campo, São Paulo, in 2005. It is aimed at analyzing knowledges revolved and incorporated by the teacher-researcher. Initially, the text brings a discussion about this research mode and the relevance of using exploratory-investigative tasks. The analysis is centered on (audio-recorded) episodes which focused on the teacher-researcher's mediation/intervention while students were working. Special attention was given to the importance of others (students, pairs and research mates), which causes some reactions of surprise and questioning, besides leading to reflexive processes. At last, it brings an analysis of the conflicts aroused by the contiguity of the teacher's and researcher's roles in a classroom environment.

Keywords: Professional knowledges; Investigating one's own practice; Exploratoryinvestigative tasks.

* Mestre em Educação pela Universidade São Francisco (USF); professora da Faculdade Famater-Chafic e da escola básica da rede estadual paulista.

**Doutora em educação e docente do Programa de Pós-Graduação Strictu Sensu em Educação da Universidade São Francisco (USF/Itatiba/SP). E-mail:adamn@terra.com.br 


\section{INTRODUCุÃO}

O presente artigo refere-se a um recorte da pesquisa de mestrado em que a professora-pesquisadora tomou sua própria prática como objeto de investigação, ao analisar suas aulas em turmas de ensino médio, nas quais os alunos estiveram envolvidos com tarefas exploratórioinvestigativas. Entende-se por tarefas exploratório-investigativas aquelas abertas (ou investigativas) que requerem que o aluno vá além do que lhe é sugerido pelo enunciado. O estudante é incentivado a exprimir suas experiências, perceber regularidades, levantar conjecturas e buscar sua validação (ou não). São tarefas que exigem claramente mais flexibilidade e criatividade do que a resolução de um problema rotineiro.

Essa modalidade de tarefa propicia reflexões constantes do(a) professor(a) sobre sua prática, seus saberes e sua gestão da aula de Matemática. Tais experiências, quando registradas e sistematizadas, podem contribuir para que o(a) professor(a) se torne investigador(a) de sua própria prática. Suas pesquisas, quando socializadas e (com)partilhadas com outros professores, não apenas dão visibilidade àquilo que acontece na sala de aula, como também possibilitam que formadores de professores tenham acesso aos saberes da ação pedagógica (GAUTHIER et al., 1998, p. 33), ou seja, saberes da experiência docente — os quais são de caráter particular - que são tornados públicos e "testados através das pesquisas realizadas em sala de aula". Trata-se de uma postura política que reconhece o(a) professor(a) como pesquisador(a) de sua prática.

Que sentido faz falar em professor(a)-pesquisador(a) no contexto brasileiro? Qual o entendimento que se tem de pesquisa da própria prática?

Neste artigo, pretende-se discutir o movimento da pesquisa da própria prática e suas contribuições para a mobilização e a apropriação de saberes profissionais. Considerando que só faz sentido falar em saberes quando estes são analisados em sua relação - com os alunos, com o contexto, com a atividade de ensino e consigo mesmo -, analisam-se, em três fragmentos de episódios documentados na pesquisa, a mediação e a intervenção da professora-pesquisadora em um contexto de resolução de tarefas exploratório-investigativas por alunos da $1^{\text {a }}$ série do ensino médio de uma escola pública paulista. 


\section{A INVESTIGAC̣ÃO DA PRÓPRIA PRÁTICA: algumas condições necessárias}

Considerar que o(a) professor(a) é um(a) produtor(a) de conhecimentos parece ser consensual entre muitos pesquisadores brasileiros. No entanto, admitir que essa produção possa ser decorrente da investigação feita pelos professores que atuam na escola básica não é uma questão tão simples. O que se entende por pesquisa do(a) professor(a)? Quem a valida e legitima?

Essas e outras questões vêm se fazendo presentes nos debates brasileiros, principalmente em Educação Matemática, em que se vêm destacando dois movimentos de professores que pesquisam a própria prática: 1) o(a) professor(a) da escola básica, por iniciativa própria e/ou como participante de grupos colaborativos, investiga problemas emergentes em suas salas de aula e, tendo o grupo como contexto para discussão e divulgação de suas investigações, gera histórias e/ou narrativas de aulas. Exemplos desse trabalho podem ser encontrados em Fiorentini e Cristovão (2006) ou Nacarato, Gomes e Grando (2008); 2) o(a) professor(a), de qualquer nível de ensino, ao ingressar num programa de pós-graduação, toma a sua própria prática como objeto de investigação. Castro (2004), Lima (2006) e Abreu (2008) exemplificam essa forma de pesquisa.

Porém, tanto em uma quanto em outra modalidade, o processo ainda está em construção - metodológica e teoricamente. Questões como: Qual o status da pesquisa que o(a) professor(a) realiza? Uma pesquisa realizada pelo(a) professor(a) em sua sala de aula deve submeterse aos cânones da academia? Se o(a) professor(a) da escola básica tornase pesquisador(a), qual seria o papel da pesquisa produzida pela academia?

Esse debate pouco tem contribuído para avanços na área. Há que se postular que ocorre uma contribuição recíproca por parte dos professores e dos acadêmicos com as pesquisas produzidas, nas duas práticas, na escola e na universidade. Defendemos que a pesquisa do(a)s professore(a)s da escola básica pode contribuir para que se venha a compreender quais conhecimentos são mobilizados na ação pedagógica e como eles são (re)significados; consequentemente, pode também contribuir para a pesquisa acadêmica e para a gestão de políticas públicas, bem como pode transformar esse(a)s professor(e/as) em consumidor(es) mais crítico(s) das pesquisas acadêmicas. 
Como nosso objetivo é discutir as contribuições da pesquisa realizada pelo(a) professor(a) da escola básica, recorremos à literatura nacional e internacional, buscando convergência com outros pesquisadores que assumem tais posturas.

Nesse sentido, partilhamos das idéias de Zeichner e DinizPereira (2005), que denominam o movimento de pesquisa do(a)s professore(a)s como pesquisa-ação. Segundo eles:

O movimento de pesquisa-ação significou um reconhecimento de que os profissionais produzem teorias que os ajudam a tomar decisões no contexto prático. Por outro lado, esse movimento internacional também pode ser entendido como uma reação contra a visão dos profissionais como meros técnicos que apenas fazem o que outros, fora da esfera da prática, desejam que eles façam e como uma rejeição às reformas "de cima para baixo" que concebem os profissionais apenas como participantes passivos. (ZEICHNER; DINIZ-PEREIRA, 2005, p. 66).

O termo pesquisa-ação, principalmente no contexto brasileiro, tem sido utilizado com os mais diferentes significados, atendendo até mesmo interesses de gestores de políticas públicas de características neoliberais, afastando-se de sua concepção original. Para evitar falsas interpretações em sua utilização, temos optado pela expressão "investigação da própria prática", tal como o faz o Grupo de Trabalho sobre Investigação (GTI), de Portugal.

Quais as razões que podem justificar a pesquisa da própria prática? Apoiando-nos em Ponte (2002), podemos argumentar favoravelmente a essa modalidade de pesquisa pelas seguintes razões: 1) possibilita ao(à) professor(a) assumir-se como protagonista do desenvolvimento curricular e profissional; 2) potencializa o desenvolvimento profissional e age como transformador da cultura escolar; 3) fornece elementos que levam à maior compreensão dos problemas educacionais e da cultura profissional.

A essas razões podem-se acrescentar outras de ordem mais geral que dizem respeito ao próprio papel do(a) professor(a) na atual sociedade. O século XXI iniciou-se marcado pelo desenvolvimento das tecnologias de informação e comunicação, provocando grandes transformações em nossa sociedade. Essa nova sociedade, também denominada "sociedade de informação" ou "sociedade do conhecimento" (HARGREAVES, 
2001), tem provocado mudanças nos cenários sociais e, consequentemente, exige mudanças no sistema de ensino.

Nesse contexto, há que se repensar a função da escola e buscar formas alternativas de atender a essas novas demandas. Para Hargreaves (2001, p. 3), houve a expansão e a democratização da educação pública nas últimas décadas, mas sem que nada fosse feito para "mudar a natureza fundamental da educação oferecida ou a maneira como os professores ensinavam".

$\mathrm{O}$ (a) professor(a) passou a ter o desafio de ensinar de modo diferente de como foi ensinado e tornou-se elemento fundamental na formação do novo cidadão do mundo globalizado e informatizado. Charlot (2005, p. 80) caracteriza esse(a) professor(a) como "agente social”, cujas funções vêm sendo modificadas:

não faz muito tempo ele tinha a tarefa de ensinar a alunos os quais se considerava normal que tivessem mais tarde a mesma posição social que seus pais (...) O que é novo é que esta futura posição social está hoje em jogo no interior da própria escola. (...) Em nossas sociedades, a escola e, portanto, o professor são o símbolo da igualdade (a escola é aberta a todos) e, ao mesmo tempo, um operador de desigualdades.

Pode-se dizer que, desde a década de 1990, estudos e pesquisas vêm sendo realizados com o intuito de propor novas alternativas educacionais, tendo a formação docente como centro dos debates. Formação entendida em seu sentido mais amplo, num movimento de experiência autêntica (LARROSA, 1998, p. 315), o encontro de alguém com a sua alteridade, num

movimento de ida e volta que contém um movimento de saída de si seguido de outro movimento de regresso a si. O ponto de partida é sempre o próprio, o cotidiano, o familiar ou o conhecido que se divide e separa de si mesmo para ir até o alheio, ou o estranho ou desconhecido e regressar depois, formado ou transformado, ao lugar de origem.

Essa concepção de formação também pode ser entendida como de desenvolvimento profissional, por se tratar de um processo que combina aspectos formais e informais, em que o(a) professor(a) se torna o sujeito de sua aprendizagem, o(a) protagonista de seu próprio conhecimento $^{2}$ profissional. Conhecimento esse entendido como sendo: 
reflexivo, plural e complexo porque histórico, provisório, contextual, afetivo, cultural, formando uma teia mais ou menos coerente e imbricada de saberes científicos - oriundos das ciências da educação, dos saberes das disciplinas, dos currículos - e de saberes da experiência e da tradição pedagógica. (FIORENTINI, NACARATO, PINTO, 1999, p. 55)

Nessa perspectiva, a pesquisa da própria prática vem ganhando destaque, uma vez que estudos vêm apontando que os modelos de formação docente, principalmente a continuada, não têm dado conta de transformar as práticas pedagógicas, pois ocorrem de forma vertical, "de cima para baixo", sem que o(a) professor(a) seja protagonista, quer de seu desenvolvimento profissional, quer do desenvolvimento curricular. As pesquisas, tanto nacionais quanto internacionais, produzidas pelo(a)s professore(a)s da escola básica vêm apresentando indícios de transformações não apenas pessoais, mas também organizacionais.

Partilhamos das idéias de Cochran-Smith e Lytle (1999, p. 321), que concebem a pesquisa da própria prática como "um estudo sistemático e intencionado dos professores sobre seu próprio trabalho na sala de aula e na escola". Para as autoras, "sistemático" refere-se às formas de registro e de documentação das experiências que ocorrem dentro e fora da sala de aula; "intencionado" indica uma atividade que, planejada pelo(a) professor(a), tem intencionalidade.

Essas autoras defendem, também, que, ao proceder assim, o(a) professor(a) está desenvolvendo conhecimento dentro de comunidades de aprendizagem - esse tipo de conhecimento é por elas denominado de "conhecimento da prática". Trata-se de um conhecimento em ação, integrando teoria e prática, e construído localmente, possibilitando o movimento entre o singular de cada professor(a) e o plural da comunidade de professores que investigam a própria prática.

Assim, quando o(a) professor(a), tanto participante de um grupo de trabalho colaborativo quanto isoladamente em sua prática docente, toma contato com as produções de outros professores, estas passam a lhe fazer sentido, a instigá-lo(a) a também se tornar um(a) professor(a) pesquisador(a), mobilizando-o para a produção de novos saberes. Essas pesquisas, ao serem divulgadas e compartilhadas, possibilitam a constituição de uma comunidade de professores que aprendem e produzem sentidos ao seu fazer pedagógico.

A aprendizagem docente é por nós concebida como um processo de produção/criação de significados. "Nesta perspectiva, a 
aprendizagem está associada a processos de compreensão do mundo material e simbólico, que pressupõem geração, apropriação, transformação e reorganizações de significações" (COLINVAUX, 2007, p. 32). Trata-se de um processo de apropriação, tal como o concebe Rogoff (1998), um processo de transformação.

A apropriação ocorre no processo de participação à medida que o indivíduo se modifica através do envolvimento na situação em questão, e essa participação contribui para a direção dos acontecimentos em evolução e para a preparação do indivíduo para envolver-se em outros acontecimentos similares. (ROGOFF, 1998, p. 134)

Essa autora caracteriza, ainda, essa apropriação como "participatória", para referir-se ao contexto em que a pessoa não apenas participa da atividade, mas é também parte dela. Uma pessoa, quando participa de um acontecimento, modifica-se, de forma que, ao participar de acontecimentos posteriores, ela já foi transformada. Entendemos que o conceito de "apropriação participatória" seja pertinente ao presente trabalho, uma vez que a pesquisa da própria prática possibilita a transformação e a apropriação de novos saberes. É um processo de (auto)formação.

Em síntese, no presente trabalho, consideramos como condições essenciais para a pesquisa da própria prática o registro intencional e sistemático do(a) professor(a)-pesquisador(a), bem como a sua participação em espaços de (com)partilhamento de ideias e saberes, os quais possibilitarão (re)elaborações conceituais e aprendizagens docentes, no que diz respeito tanto à prática docente quanto à própria metodologia da pesquisa.

Esses pressupostos nortearam nossa pesquisa, cujo recorte apresentamos a seguir.

\section{O CONTEXTO DA INVESTIGAC̣ÃO}

O presente trabalho refere-se a uma pesquisa de mestrado, realizada num programa de pós-graduação em educação. A investigação foi realizada pela primeira autora deste trabalho - aqui denominada professora-pesquisadora - e orientada pela segunda - aqui denominada 
professora-orientadora. Todo o processo de construção do referencial teórico, de documentação e análise foi por nós compartilhado.

Caracterizada como análise de um caso, de abordagem qualitativa, a pesquisa investigou a própria prática da professorapesquisadora num contexto de sala de aula com tarefas exploratórioinvestigativas. O recorte aqui apresentado refere-se ao trabalho com alunos da $1^{\mathrm{a}}$ série do ensino médio, em uma escola pública estadual de São Bernardo do Campo/SP, durante o ano de 2005.

Por que a escolha da exploração de tarefas exploratórioinvestigativas como cenário para investigação da própria prática? Embora já tenhamos anunciado anteriormente nosso entendimento sobre esse tipo de tarefa, julgamos necessário ampliar sua caracterização e evidenciar a articulação de um trabalho dessa natureza com a investigação da própria prática.

Inicialmente, apoiamo-nos na definição dada por Ponte et al. (1997). Esses autores utilizam a denominação "tarefa investigativa" e a caracterizam como uma questão aberta, de cunho problemático, cuja realização pode demorar um conjunto de aulas. Ao aluno, diante das tarefas, cabe formular objetivos mais precisos para investigar, formular conjecturas, testá-las e, eventualmente, demonstrá-las.

Uma tarefa, para ser investigativa, precisa, durante a dinâmica das aulas, passar por três momentos distintos, definidos por Tudella et al. (1999): 1) introdução da tarefa; 2) desenvolvimento da tarefa; 3) discussão/reflexão final. Este último momento é fundamental, pois é nele que se promove a discussão dos processos de resolução, conduzindo para a generalização e a validação das conjecturas. No entanto, nossa experiência evidenciou que uma tarefa nem sempre se constitui em uma investigação, já que depende da mobilização dos alunos para a sua resolução. Assim, o acréscimo da palavra "exploratório" acaba por garantir uma tarefa mais aberta, que pode (ou não) gerar uma investigação.

Entendemos que esse tipo de tarefa proporciona o envolvimento dos alunos e do(a) professor(a) em uma dinâmica permeada por troca de conhecimentos, criatividade, desenvolvimento de atitudes indagadoras e de linguagem matemática (oral e escrita) e proporciona para o(a) professor(a) um momento passível de reflexão de sua própria prática. $\mathrm{O}(\mathrm{a})$ professor(a) torna-se, durante o processo, um aprendiz e amplia seu 
repertório de saberes - a escolha e a seleção de tarefas; a forma de implementar a dinâmica nas aulas; e o momento de socialização e discussão, com as reflexões coletivas. Torna-se, ao mesmo tempo, um(a) pesquisador(a) de sua prática.

A dinâmica das aulas com tarefas exploratório-investigativas envolve interações dos alunos entre si e dos alunos com o(a) professor(a). Duas formas de interação podem ser destacadas: a comunicação e a negociação de significados. A primeira refere-se à interação dos diversos intervenientes na sala de aula, utilizando uma linguagem própria, que é um misto de linguagem corrente e linguagem matemática. A negociação de significados diz respeito ao modo como alunos e professor(a) expõem uns aos outros o significado que atribuem aos conceitos e aos processos matemáticos, como os aperfeiçoam e como os ajustam ao conhecimento matemático indicado pelo currículo.

Assim, em contextos investigativos, a comunicação proporciona a oportunidade de expressão das ideias matemáticas que se encontram em circulação naquele ambiente, possibilitando a apropriação, a transformação e a reorganização de significações (COLINVAUX, 2007).

Esses pressupostos nortearam a realização da pesquisa. O material documentado consistiu de: registros escritos dos alunos (estratégias utilizadas na resolução das tarefas e relatórios), audiogravação em sala de aula e diário de campo da professora-pesquisadora.

Para o presente trabalho, destacaremos os saberes mobilizados e apropriados no contexto da pesquisa. Para tal, escolhemos um dos eixos de análise da pesquisa, o qual evidencia as reflexões, os conflitos e as transformações da professora-pesquisadora, num ambiente de mediação e intervenção com os alunos, durante a realização das tarefas exploratórioinvestigativas.

\section{A MOBILIZAC̣ÃO E A APROPRIAC̣ÃO DE SABERES EM MOMENTOS DE INTERAÇ̃̃O NA SALA DE AULA: o papel da intervenção da professora}

A opção por este eixo da pesquisa justifica-se por ter sido a análise da intervenção da professora, a nosso ver, fundamental para a reflexão e para a tomada de consciência da prática docente. 
Como já destacado, na realização de tarefas exploratórioinvestigativas, as interações conduzem a uma dinâmica mais rica, pois os alunos desenvolvem grande parte da tarefa em colaboração, compartilhando pensamentos matemáticos.

Em termos educativos, é fundamental permitir que os alunos interajam, aprendendo a discutir e a argumentar em defesa de suas opiniões. Numa concepção histórico-cultural, o homem, na sua relação com os outros e com o mundo, "produz instrumentos auxiliares técnicos e simbólicos — que constituem sua atividade prática, mental, possibilitando a ele transformar o mundo enquanto se constrói simbólica, histórica e subjetivamente" (VYGOTSKY citado por SMOLKA; NOGUEIRA, 2002, p. 82).

Fontana e Cruz (1997, p. 66) argumentam que, embora o aluno chegue à escola já dominando inúmeros conhecimentos, faz-se necessário um processo educacional sistematizado, pois, por meio deste, o aluno reelabora esses conhecimentos mediante o estabelecimento de uma nova relação cognitiva com o mundo e com seu próprio pensamento.

Nesse contexto, a relação de ensino (professor(a)-alunos) deve ser enfatizada como de acompanhamento, orientação, indagação, ou seja, as situações têm que ser compartilhadas mutuamente, visando a possibilitar o acesso do aluno às atividades intelectuais ainda não incorporadas por ele. Essa relação deve ser perpassada pela intervenção pedagógica, a qual é carregada de intencionalidade.

Alguns pressupostos da teoria vygotskiana possibilitam-nos perceber a importância da intervenção do(a) professor(a) para o desenvolvimento do pensamento dos alunos. A intervenção pedagógica, quando feita de maneira intencionada, pode contribuir para que os alunos avancem no raciocínio e dele tomem consciência, para responder ao outro. Oliveira (1997, p. 62) considera que “a intervenção de outras pessoas - que no caso da escola, são o(a) professor(a) e os demais alunos - é fundamental para a promoção do desenvolvimento do indivíduo”.

Para Fontana (2000, p. 19), a mediação do outro faz emergir na mente do aluno um sistema de processos complexos de compreensão ativa e responsiva, juntamente com as experiências e as habilidades por ele já adquiridas. As intervenções escolarizadas têm importância nesse sentido, pois ampliam, sob vários aspectos, as condições de produção do processo de elaboração conceitual. 
Para ilustrar nossas posições, selecionamos o episódio a seguir ${ }^{3}$, com momentos reais de intervenção da professora- pesquisadora durante a ação pedagógica, em um dos grupos de trabalho. Este episódio foi audiogravado:

Fragmento 1: Os alunos estavam diante da tarefa "triângulos com palitos", cujo enunciado era:

a) Com palitos de sorvete, construa um triângulo. Quantos palitos você usou?

Continue a formar outros triângulos, como na figura:

b) Prolongue as construções e analise a sequência, procurando descobrir quantos palitos usaria para formar 10 triângulos. triângulos?

Quantos palitos seriam usados para formar um número $\mathbf{n}$ de

Que outras observações você pode tirar dessa sequência?

(1) A3: Eu percebi uma coisa. Sempre que vai aumentar um triângulo, aumenta só dois palitos.

(2) P: Acharam pra 10 palitos?

(3) A1: Achamos, e achamos pra 65.

(4) P: Quanto que dá pra 10?

(5) $A 2: 22$.

(6) $P:$ Não.

(7) $A 1,2,3:$ Não!

(8) A3: Não, C., porque não é o dobro, porque só aumentam 2.

(9) A2: Vamos fazê de $3 \mathrm{em} \mathrm{3,} \mathrm{ó} \mathrm{1,2} \mathrm{até} \mathrm{aqui} \mathrm{tem} \mathrm{quantos?}$

(10) A3: E aí sabe o que nós fižemos? Nós fizemos 5 triângulos, ai nós multiplicamos por 2 o número total de 5 triângulos, mas tá errado, porque só vai aumentar 2 palitos.

(11) P: Isso aí.

(12) A1: Pera aí! $3,5,7$ ! 


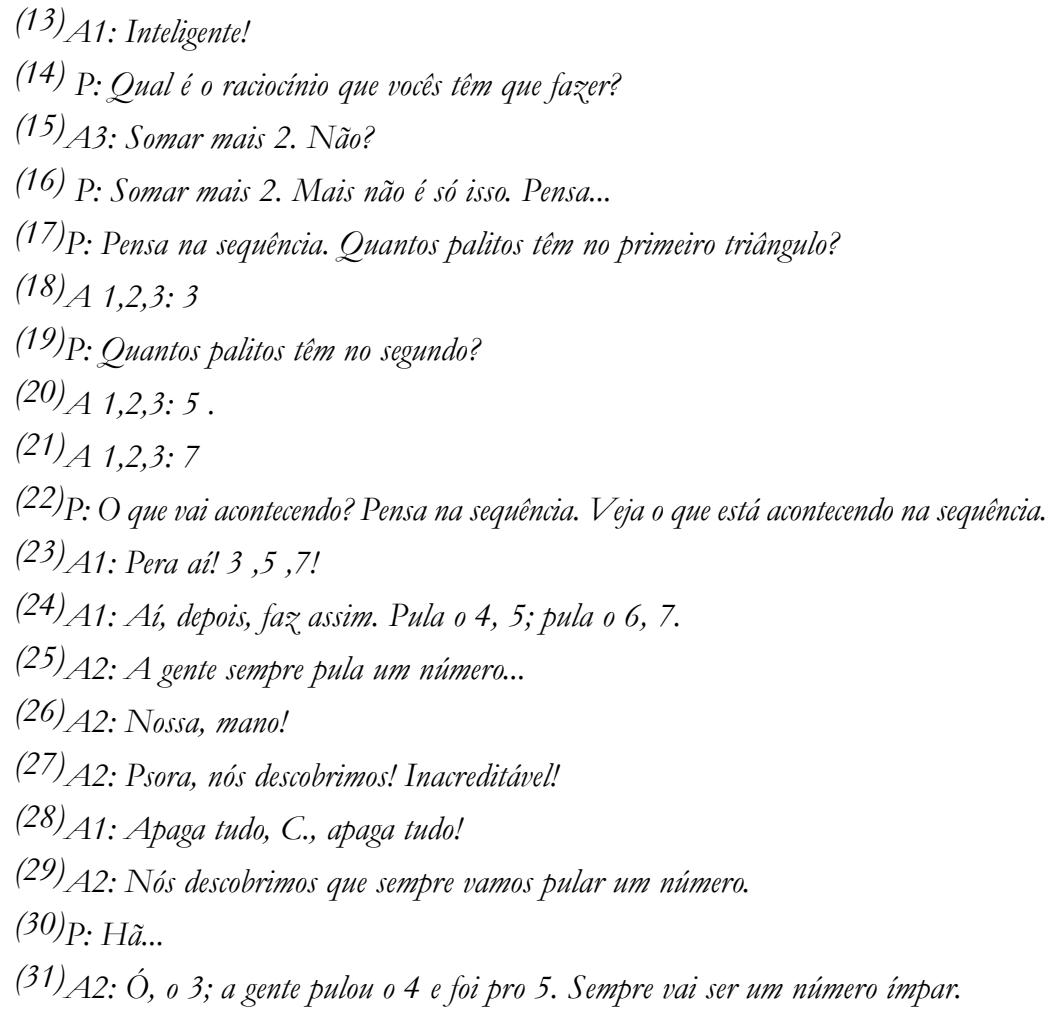

A interação entre a professora e os alunos em tarefas de natureza exploratório-investigativas é fundamental, no sentido de orientar a compreensão das conjecturas já formuladas, possibilitando, assim, que os alunos avancem nas novas conjecturas e nos raciocínios. Isso se evidencia nas falas 2, 4 e 6, quando a professora adotou o papel de mediadora e de orientadora, dirigindo a atenção dos alunos para que percebessem a regularidade presente na sequência.

A intervenção da professora propiciou que o aluno parasse para pensar, revisse suas posições e se surpreendesse com o inesperado, aquilo que contradizia suas certezas - como nas falas de 6 a 10. Quando a professora disse "Não", ela estimulou os alunos para o movimento de pensar sobre, de surpreender-se com as conjecturas até então postas e possibilitou que se colocassem na busca do "erro", como se pode constatar na fala de A3, quando ele chamou a atenção dos colegas para o erro cometido. Tal identificação foi validada pela professora na fala 11. A partir daí, os alunos iniciaram novas conjecturas. 
Nos próximos momentos de intervenção, a professora assumiu um papel mais ativo e comportou-se como se estivesse trabalhando junto com os alunos, com perguntas (falas 14, 16, 17, 19 e 22) que visavam a fazer com que os alunos observassem e descrevessem oralmente as regularidades, propiciando uma tomada de consciência por parte deles.

Com essa intervenção, a professora contribuiu para o processo mental desenvolvido pelos alunos na atividade, fazendo com que eles concluíssem que seriam números ímpares e vibrassem com as descobertas - falas 26 a 29. Essas descobertas foram novamente validadas pela professora no provável gesto de aprovação, quando disse : Hã... (fala 30).

De acordo com Fontana (2000, p. 22), a mediação do(a) professor(a) é importante para o aluno poder, com base em seus conceitos espontâneos, raciocinar, junto com a professora, tentando reproduzir as operações lógicas por ela utilizadas.

A professora, neste caso, precisamente nas falas 17 e 19, forneceu aos alunos informações sobre estratégias que eles poderiam usar para encontrar uma conjectura; nas falas de 23 até 31, podemos notar o primeiro indício de generalização por parte dos alunos, propiciada pelas questões postas pela professora.

Fragmento 2: Este fragmento refere-se ao trabalho de um grupo (audiogravado), quando os alunos realizavam a tarefa "O que têm em comum", cujo enunciado era:

a) Calcule:

$$
2^{3}-2=\quad 3^{3}-3=\quad 4^{3}-4=\quad 5^{3}-5=\quad \ldots
$$

b) Investigue se existem características comuns entre os números que se obtêm através deste processo.

(1) P: Tem três perguntas aqui no quadro que têm a ver com a tarefa. Que tipo de número se obtém? O que tem quando se calcula com números consecutivos? Que características se observam com expoentes diferentes? Então são algumas características que vocês podem estar observando aqui. Vocês têm 50 minutos pra fažer, sem preguiça mental. Aí cada um pode seguir pelo caminho que quiser.

(2) A2: Não, 4, 6, 8, 10.

(3) A2: Professora?

(4) P: O que vocês obtêm quando se calculam números consecutivos? Eu não sei se eles estão 
aí. Tem que observar a sequência. Vamos fazer o seguinte: tem 3 pontinhos aqui, não tem? (5) A1: Sim.

(6) P: Far mais um pouquinho, vê o que está acontecendo aqui, daqui pra cá, dá uma olhadinha.

(7) A1: Daqui pra cá?

(8) P: Ó, decompõe esse número aqui, o que eu tenho aqui. 2. Como a gente decompõe esse número aqui? Depois, como nós decompomos esse número aqui? É como escrevemos na forma de multiplicação?

(9)P: É. Decompõe aqui. E esses aqui são o quê? 4, 6, 8, 10, são o quê?

(10)P: Que mais?

(11) A2: São consecutivos.

(12) P: Tá, pares consecutivos? Números pares e mais o quê? Se tiver 2-4-6-8-10.

(13) A4: de 2.

(14)P: Então, eu posso decompor isso aqui. Faz a decomposição.

(15) P: Deixa-me dar uma dica pra vocês. Quando vocês fizerem o resultado, observem o resultado, que números são, que números se obtêm; se forem múltiplos, são pares múltiplos de quem? Eu posso decompor esses números em multiplicação?Vamos pensar tudo isso pra ver o que está acontecendo.

De acordo com Ponte, Brocardo e Oliveira (2003), a interação que o(a) professor(a) estabelece com os alunos nas aulas investigativas é bem diferente da que ocorre em outros tipos de aula, pois leva-os a confrontarem-se com alguns dilemas e dificuldades. Desse modo, o(a) professor(a), durante o acompanhamento aos alunos e em suas intervenções, deve tentar atingir um ponto de equilíbrio entre os dois pólos: a autonomia dos alunos e a garantia de que o trabalho deles seja significativo, do ponto de vista da disciplina Matemática, desempenhando, assim, papeis diferenciados.

O fragmento anterior evidencia momentos de intervenção da professora, que tanto incentivava os alunos quanto os direcionava (falas 1, 4, 6 e 8). Nesta tarefa, especificamente, os alunos tiveram muitas dificuldades. A forma como a professora conduziu o processo evidencia, em vários momentos, sua dificuldade em desempenhar papeis diferenciados exigidos no decorrer de uma aula com investigações/ explorações.

Fontana (2000, p. 38) corrobora nossa análise quando afirma:

O grande desafio foi, e penso que continua sendo, em qualquer trabalho educativo, aprender a esperar o movimento do outro, o seu tempo de 
elaboração, e a respeitar as elaborações desse outro... Resistir à tentação de impor o caminho que pareça melhor, não só aos nossos próprios objetivos, mas também para o(s) outro(s). E, nesse jogo, a busca do equilíbrio entre evitar a imposição de autoritarismos, sem resvalar para uma postura de falsa neutralidade diante das contradições observadas.

$\mathrm{Na}$ fala 4, a professora tentou fazer relação com uma tarefa com números consecutivos já conhecida pelos alunos, mas, na fala 8 , adotou uma postura expositiva: tentou conduzir os alunos para a melhor exploração da tarefa, pela decomposição, apontando para os números, ansiosamente, ensinando como escrevê-los na forma de multiplicação ${ }^{6}$.

Sem perceber, ela conduziu o processo para o conceito que desejava, pois havia feito a tarefa antes de aplicá-la; direcionou os alunos para o caminho que ela escolheu, ou seja, não deu chance de eles criarem suas saídas ou soluções. As marcas da sua intervenção estão presentes do começo ao fim. Praticamente toda a tarefa é feita à luz dos critérios estabelecidos pela professora. Esse momento fica evidente nas falas $14 \mathrm{e}$ 15 , quando ela induziu o pensamento dos alunos, praticamente dando a solução para a tarefa.

Esse episódio revela o momento de conflito entre a docência e a pesquisa, por parte da professora. Como docente, precisava garantir que os alunos se mobilizassem para a atividade, mas, como ninguém se mobiliza diante daquilo que não compreendeu, a professora direcionou, "deu dicas"; como pesquisadora, ao "impor um caminho", retirou da atividade a possibilidade de investigação por parte dos alunos, indo na contramão dos seus objetivos ao trabalhar com esse tipo de tarefa em sua pesquisa. Mas tal tomada de consciência só foi possível no momento de análise do material audiogravado.

Como outros alunos apresentavam dificuldades na realização da tarefa, ocorreram outras formas de intervenção da professora - conforme destacado a seguir.

Fragmento 3: Ainda na realização da tarefa "O que têm em comum":

(1)P: (...) O que vocês pensam disso aí? Observem as sequências; observem o que está acontecendo daqui pra cá e, olha só, vocês viram múltiplos de 6 e de quem mais? Pra ser múltiplo de 6, qual é a regrinha pra ser múltiplo de 6? Lembram? Ele tem que ser também o quê? Eles são múltiplos de 6 e de quem mais? 
(2) A3: São pares.

(3) P: São pares múltiplos de quem?

(4) A4: 2.

(5)P: E de quem mais?

(6) A1: 3?

(7) P: 3! Por quê? Ó, 24 não é múltiplo de 3 ? 6 não é múltiplo de 3? 60 não é múltiplo de 3? Eles não são múltiplos de 2 também? Porque pra ser múltiplo de 6 tem que ser múltiplo de 2 e 3 também, ao mesmo tempo. Regrinha! Anota tudo isso e pensem na sequência. Eu quero que vocês façam o relatório.

Diante da ausência de explorações, por parte dos alunos, a professora tentou (falas 1 e 3) reformular sua estratégia de intervenção, estabelecendo relações com conceitos de múltiplos, que eles já conheciam.

$\mathrm{Na}$ fala 7, identificamos, novamente, uma intervenção expositiva, com o uso da palavra "regrinha", direcionando os alunos e evidenciando marcas da formação da professora, do modo como ela aprendeu. Nesse contexto, expor "regras" não é o melhor caminho, pois o aluno deve criar, conjecturar e discutir suas próprias soluções.

Além disso, constata-se ainda, nessa fala 7 , que a professora fez a pergunta aos alunos (Por quê?), sem, no entanto, dar-lhes tempo para pensar e responder. Ela mesma continuou falando, formulando outras questões, as quais culminaram com a "regrinha".

Nesses dois últimos episódios, a intervenção não foi adequada, o que nos conduz a algumas reflexões sobre essa análise, quando se confrontam os papeis de professora e pesquisadora. Qual o lugar da professora na sala de aula? Qual o lugar da professora na pesquisa? Claramente, estamos diante de um conflito: a professora que queria ensinar e, ao mesmo tempo, queria que tudo desse certo, afinal, era sua pesquisa de mestrado.

Para os alunos, tudo era novo. As dificuldades eram grandes, até mesmo a forma do enunciado da tarefa. Esse fato, aliado aos conflitos da professora, determinou, em alguns momentos, a posição que a professora assumiu no contexto. Assim, o que prevaleceu foi a concepção de ensino centrado no(a) professor(a), concepção vigente na história de formação da professora.

Conforme argumenta Fontana (2000, p. 39), para a professora acertar esses passos e lugares não é casual, nem espontâneo. Na prática 
construída em sala de aula, ela deve ser a mediadora permanente. A explicitação dessa prática (os saberes da ação pedagógica) possibilita-nos perceber os elementos que dificultam e limitam o trabalho do(a) professor(a).

Com as mediações/intervenções da professora-pesquisadora, percebemos momentos em que as interações (professor(a) e aluno) possibilitaram avanços nas conjecturas dos alunos, de forma que eles mobilizassem seus conhecimentos matemáticos. Neste tipo de dinâmica, as intervenções devem ser feitas no momento adequado, para que os alunos possam criar livremente suas soluções.

Se, por um lado, aconteceram momentos em que a professorapesquisadora conduziu o raciocínio dos alunos, com excesso de intervenções durante a tarefa, por outro, ocorreram momentos em que as intervenções possibilitaram que os alunos avançassem autonomamente. Mas, tanto em um quanto em outro caso, os registros foram fundamentais para a produção de significados a partir da reflexão sobre a sua prática pedagógica.

Em seu diário de campo, a professora-pesquisadora destacou, por várias vezes, que "não deveria ter dado essa tarefa", porque os alunos tiveram muitas dificuldades; porém, no momento da análise, evidenciouse a importância dessa tarefa, pois foi ela que possibilitou que a professora-pesquisadora "olhasse" para si mesma como professora e mediadora na sala de aula.

\section{SABERES APROPRIADOS A PARTIR DA INVESTIGAC̣ÃO DA PRÓPRIA PRÁTICA: algumas sínteses}

O estudo cujo recorte foi aqui apresentado e analisado, por ser sistematizado e intencionado, tal como concebido por Cochran-Smith e Lytle (1999), possibilitou à professora a investigação de sua prática e a mobilização e a apropriação de conhecimento profissional. A análise dos episódios de sala de aula possibilitou a reflexão sobre o trabalho desenvolvido. Buscou-se a compreensão de algumas posturas de intervenção durante o trabalho, o que favoreceu aprendizagens sobre o processo de ensino. Como Freire (1996, p. 47) afirma: "Ensinar não é transferir conhecimento, mas criar possibilidades para sua própria 
produção ou a sua construção”. Foi o que ocorreu durante as aulas, na intervenção da professora e na sua reflexão, buscando significações para a prática e apropriação de saberes, relativos tanto ao trabalho com tarefas exploratório-investigativas quanto aos processos de intervenção em sala de aula.

O processo de análise foi fundamental para o desenvolvimento profissional da professora-pesquisadora.

Uma das evidências desta pesquisa é que o(a) professor(a) que se dispõe a investigar a própria prática não pode desempenhar essa tarefa de modo solitário. Ele(a) necessita do outro - que podem ser os pares na própria escola, os pares num programa de pós-graduação, o grupo (se ele fizer parte de um), os próprios alunos na sala de aula e, no caso de mestrado, por exemplo, o orientador e os espaços de comunicação e divulgação da pesquisa.

As transformações vividas pela professora-pesquisadora nesta investigação foram significativas e pelo menos três momentos que contaram com a contribuição dos pares possibilitaram maiores reflexões e novos olhares para o trabalho. O primeiro deles foi durante o Exame de Qualificação. As análises e os questionamentos postos pelas professoras que constituíram a banca examinadora mobilizaram a pesquisadora a repensar e refletir sobre o processo vivido e a ter um olhar mais acurado sobre o material documentado.

O segundo foi a participação no IX EBRAPEM (Encontro Brasileiro de Pós-Graduandos em Educação Matemática), em novembro de 2005, no qual ela se envolveu em sessões coordenadas em que se debatiam pesquisas sobre a própria prática e sobre o uso de tarefas investigativas portanto, a professora estava inserida numa comunidade de investigação e de aprendizagem em torno do uso das tarefas exploratório-investigativas. A discussão com os pares, o confronto de pontos de vista, as similaridades dos problemas vivenciados na prática e na pesquisa com os de outras pesquisas foram fundamentais para o processo de análise do material documentado. A partir daí, foi possível enxergar a riqueza do material no momento de análise dos trabalhos dos alunos, privilegiando as intervenções/mediações da professora e ressaltando também a importância do papel do outro nas relações de ensino.

Bakthin (2003, p. 21) denomina essa forma de olhar a relação consigo mesma e a relação com o outro de "excedente de visão", e afirma: 
"porque nesse momento e nesse lugar, em que sou o único a estar situado em um dado conjunto de circunstâncias, todos os outros estão fora de mim". Refere-se à visão de mundo sobre a presença do sujeito no mundo, sua unicidade e sua característica de insubstituível. Segundo ele, "o sujeito do conhecimento como tal não ocupa lugar concreto determinado na existência" (p. 22); é, assim, único e irredutível, mas é também carente, necessita do outro para complementar-se, para que juntos construam significados comuns. Dessa forma, ambas - professora-pesquisadora e professora-orientadora - necessitaram desse olhar externo para problematizar, para trazer questões para a reflexão e possibilitar o avanço no trabalho.

A possibilidade de compartilhar as experiências vividas é que contribui para que o(a) professor(a) minimize a solidão do trabalho docente. A pesquisa evidenciou a importância do outro, que provoca estranhamentos, questiona, compartilha ideias, colabora na solução de problemas e de desafios postos pela prática.

O terceiro e mais rico momento vivenciado pela professorapesquisadora - potencializador de suas transformações — foi durante o processo de análise do material dos alunos, momentos esses compartilhados com a professora-orientadora. Foram identificados registros interessantes de alunos considerados "ruins", não só pela professora, mas por toda a escola, o que funcionou como alerta para as nossas (pré)concepções sobre os alunos. Percebemos também a importância de dar voz e ouvidos aos alunos; a comunicação é o elo principal. Nas transcrições, foram evidentes as manifestações de interesse pelo trabalho, porque os alunos estavam mobilizados (CHARLOT, 2005), tinham desejo de aprender, participavam da atividade, não era a professora que trabalhava sozinha. Era, sim, um trabalho de todos, compartilhado.

Nesse movimento dialógico da prática vivenciada com o outro, os teóricos com quem dialogamos, as contribuições dos pares e as manifestações dos alunos, a professora-pesquisadora mobilizou saberes que possibilitaram atribuir novos significados à sua prática. A professora construiu saberes, nessa prática, que implicaram a mudança de sua concepção de ensino. Ensinar não é somente transmitir conteúdos ou conceitos, mas ir além, considerar as relações humanas, as trocas que produzem significados para ambas as partes. Dessa maneira, 
concordamos com Charlot (2005, p. 58): "não existe saber (de aprender) se não está em jogo a relação com o mundo, com os outros e consigo”. Ensinar é criar possibilidades para que a aprendizagem ocorra. A professora-pesquisadora conseguiu, com este trabalho, enxergar algo que dificilmente conseguiria sem o registro da prática, como, por exemplo, as marcas de sua formação durante sua trajetória estudantil e em início de carreira, em que predominava um modelo de ensino de Matemática centrado no(a) professor(a).

Evidenciou-se também, com esta pesquisa, que, ao falar de reflexão ou de pesquisa da própria prática, não há como considerá-las coisas distintas, pois há interdependência entre elas. Os nexos da pesquisa são indissociáveis da reflexão. Entendemos que a formação é, na verdade, a autoformação, ou seja, os saberes iniciais são confrontados com as experiências práticas, vivenciadas no contexto escolar. O processo vivido, em meio a conflitos, angústias, idas e vindas nas discussões com os pares desencadeou reflexões críticas sobre a prática da professora-pesquisadora e sobre o processo de orientação e formação, por parte da professoraorientadora.

Segundo Zeichner e Diniz-Pereira (2005), relatos de experiência em todo o mundo vêm destacando o quanto as pesquisas realizadas pelo(a)s professore(a)s em salas de aula vêm contribuindo para o seu desenvolvimento profissional e para a transformação das escolas. “Também se tem argumentado que a pesquisa dos educadores estimulará mudanças positivas na cultura e na produtividade das escolas, além de poder aumentar o status da profissão de magistério na sociedade" (p. 67). Nesse sentido, podemos afirmar que a pesquisa da própria prática possibilita reflexões, mobilização de saberes e, consequentemente, desenvolvimento profissional. Como destacado pela professorapesquisadora na dissertação:

Posso concluir que construí saberes pedagógicos, no momento que comecei a compreender a minha prática; primeiro com aplicação das tarefas, depois com a leitura dos dados, e por último com sua análise e as leituras realizadas, que possibilitaram uma profunda reflexão sobre a professora neste contexto. (LIMA, 2006, p. 181)

Um dos maiores conflitos que a professora-pesquisadora vivenciou foi a justaposição de papeis: professora e pesquisadora. Ela 
vivia um duplo conflito: de um lado, introduzir uma nova metodologia em sala de aula - o uso de tarefas exploratório-investigativas - e, de outro, coletar dados para a pesquisa. Como professora, tinha de cumprir sua função primordial: garantir um ambiente de aprendizagem aos alunos. Mas a situação de sala de aula é complexa, e essa complexidade tornou-se maior ainda nesse caso específico: a professora era nova na escola e era seu primeiro contato com esses alunos, que não estavam acostumados a uma dinâmica de aula de Matemática que descentraliza o poder do(a) professor(a) como transmissor(a) de conhecimentos. Isso exigia intervenções adequadas da professora: como questionar os alunos para que eles avançassem nos raciocínios? Como torná-los mobilizados para a realização da tarefa? Como garantir a aprendizagem?

Prevendo dificuldades na aplicação das tarefas exploratórioinvestigativas, ao iniciar o trabalho com essas turmas de $1^{\text {a }}$ série de ensino médio, a professora-pesquisadora teve o cuidado de vivenciar previamente uma série de situações em que os alunos deveriam trabalhar em grupos e produzir registros escritos das atividades realizadas. No entanto, a sala de aula é imprevisível e nem sempre as coisas acontecem como planejado. Além disso, como professora, precisava garantir que todos os alunos saíssem das situações de resolução de tarefas com apropriação de conhecimentos matemáticos. Dessa forma, as intervenções da professora nem sempre ocorreram dentro daquilo que era previsto, em razão dessas exigências momentâneas, que se tornaram evidentes no momento da análise do material documentado.

Como pesquisadora, havia a preocupação em documentar o máximo possível das situações vividas em sala de aula, para poder contar com suficiente material para análise. No entanto, muitos foram os imprevistos: a filmadora queimou, porque um funcionário da escola desligou a chave de energia quando a filmagem estava sendo realizada; os barulhos externos - além do barulho na sala de aula, natural para uma atividade em que os alunos estão trabalhando em grupos — interferiam nas audiogravações. Estaria conseguindo documentar adequadamente a experiência para posterior análise?

No que diz respeito à mobilização e à produção de novos saberes, a experiência vivenciada foi altamente significativa. A continuidade das tarefas, a vivência com os alunos e a experiência documentada possibilitaram à professora-pesquisadora ampliar saberes e aprender cada 
vez mais. De uma tarefa para outra, práticas eram incorporadas - algumas mais técnicas, como a própria formatação das tarefas; outras relativas à dinâmica da sala de aula, ao modo como a professora organizava os alunos para o trabalho: as posições dentro do grupo, os registros escritos, o uso dos recursos didáticos e os registros para a reflexão final.

O contexto possibilitou refletirmos sobre questões que emergem na realidade da sala de aula, da tecedura de teoria e prática, viabilizando a construção de um espaço de expressão das motivações, dos interesses e dos valores da professora e da pesquisadora. Nesse contexto, a utilização de tarefas exploratório-investigativas foi altamente potencializadora para a produção de saberes profissionais.

Enfim, o compartilhamento da produção deste texto e da análise do material de sala de aula revelou novos sentidos sobre a utilização de tarefas exploratório-investigativas e sobre a investigação da própria prática, tanto para a professora-pesquisadora quanto para a professoraorientadora.

Evidentemente, não podemos olhar para o movimento da pesquisa da própria prática como a "tábua de salvação" para os problemas da escola pública. A pesquisa aqui destacada foi realizada em meio a muitas dificuldades e, pode-se até mesmo afirmar, por insistência e utopia de uma professora que acreditou ser possível realizá-la, apesar de todas as adversidades que foi encontrando pelo caminho: suas limitações teóricas decorrentes de programas de formação inicial que não têm dado conta de "preparar" o(a) professor(a) para a complexidade da sala de aula e da realidade da escola pública; as dificuldades inerentes à introdução de uma nova metodologia em sala de aula - as resistências dos alunos e a insegurança da professora; as condições de trabalho docente, com classes heterogêneas e superlotadas, escolas sem condições físicas e humanas: o barulho causado pelo ambiente externo tumultuado, em razão da falta de professores e de funcionários, interferia na dinâmica interna da classe e a carga horária docente não possibilitava tempo para estudos, para reflexão e, no caso da pesquisadora, nem mesmo para a produção de seu diário de campo após a realização das aulas. Nesse sentido, Zeichner e DinizPereira (2005, p. 71) expressam o sentimento que vivemos:

No Brasil, apesar de haver iniciativas de parcerias entre universidades e Secretarias de Educação para o desenvolvimento de programas de formação continuada que incluam a realização de pesquisas por parte dos professores, 
as condições de trabalho da maioria dos educadores são tão precárias que às vezes pode parecer piada de mau gosto falar em pesquisa desenvolvida por professores na escola.

No entanto, apesar dessa realidade, a professora não desanimou e manteve seu propósito.

No que diz respeito à metodologia das tarefas investigativas, foi possível compreender que esse tipo de prática, que privilegia as relações humanas e a atividade intelectual dos alunos, possibilita um avanço na aprendizagem destes e, consequentemente, produz reflexões e (re)elaborações nos saberes docentes, constituindo-se como uma possibilidade para um sistema escolar mais democrático e emancipatório, corroborando o pensamento de Pimenta (2002, p. 43): “O professor pode produzir conhecimento a partir da prática, desde que na investigação reflita intencionalmente sobre ela, problematizando os resultados obtidos com o suporte da teoria. E, portanto, como pesquisador de sua própria prática”.

Podemos afirmar que vivemos aquilo que Larrosa (1998) denomina de "experiência formativa". Dessa "viagem" saímos transformadas, compartilhamos histórias e apropriamo-nos de forma "participatória" (ROGOFF, 1998) de saberes sobre a prática pedagógica e sobre a pesquisa dessa prática. Desenvolvemo-nos profissionalmente.

\section{REFERÊNCIAS}

ABREU, Maria da Graça dos Santos. Uma investigação sobre a prática pedagógica: refletindo sobre a investigação nas aulas de Matemática. 2008. 192p. Dissertação (Mestrado em Educação). Universidade Federal de São Carlos, São Carlos/SP.

BAKHTIN, Mikhail. Estética da criação verbal. Trad. Paulo Bezerra. São Paulo: Martins Fontes, 2003.

CASTRO, Juliana Facanali. Um estudo sobre a própria prática em um contexto de aulas investigativas de Matemática. 2004, 197p. Dissertação (Mestrado em Educação - Educação Matemática). Faculdade de Educação, Unicamp, Campinas, SP.

CHARLOT, Bernard. Relação com o saber, formação dos professores e globalização: questões para educação hoje. Porto Alegre: Artmed, 2005.

COCHRAN-SMITH, Marilyn; LYTLE, Susan L. Relationships of knowledge and practice: teacher learning in communities. Review of Research in Education. USA, 24, p. 249-305, 1999

COLINVAUX, Dominique. Aprendizagem e construção/constituição de conhecimento: reflexões teórico-metodológicas. Pro-Posições. Faculdade de Educação da Universidade Estadual de Campinas, Campinas, SP, v. 18, n. 3(54), p. 29-51, set./dez. 2007.

ERNEST, Paul. Investigações, resolução de problemas e Pedagogia. In: ABRANTES, P., 
LEAL, L. C.; PONTE, J. P. (Org.). Investigar para aprender matemática: textos selecionados. Lisboa: Projeto MPT e APM, 1998. p. 25-48.

FIORENTINI, Dario; NACARATO, Adair Mendes; PINTO, Renata Anastácio. Saberes da experiência docente em Matemática e educação continuada. Quadrante - Revista Teórica e de Investigação. Lisboa, v. 8, p. 33 -59, 1999.

FIORENTINI, Dario; CRISTOVÃO, Eliane Matesco. (Org.). Histórias e investigações de/em aulas de Matemática. Campinas, SP: Alínea, 2006.

FONTANA, Roseli A. Cação; CRUZ, Maria Nazaré. Psicologia e trabalho pedagógico. São Paulo: Atual, 1997.

FONTANA, Roseli A. Mediação pedagógica na sala de aula. 3 ed. Campinas, SP: Autores Associados, 2000. (Coleção Educação Contemporânea).

FREIRE, Paulo. Pedagogia da autonomia: saberes necessários à prática educativa. 31 ed. São Paulo: Paz e Terra, 1996.

GAUTHIER, Clermont et al. Por uma teoria da pedagogia: pesquisas contemporâneas sobre o saber docente. Ijuí: Unijuí, 1998.

HARGREAVES, A. Teaching as a paradoxical profession. In: ICET - WORLD ASSEMBLY: TEACHER EDUCATION, 46, 2001. Santiago, Chile, 2001. 22p. CDROM.

LARROSA, Jorge. Pedagogia profana: danças, piruetas e mascaradas. Porto Alegre: Contrabando, 1998.

LIMA, Claudia Neves do Monte Freitas de. Investigação da própria prática docente utilizando tarefas exploratório-investigativas em um ambiente de comunicação de idéias Matemáticas no Ensino Médio. 2006. 204p. Dissertação (Mestrado em Educação). Programa de Pós-Graduação Stricto Sensu em Educação, Universidade São Francisco, Itatiba, SP.

NACARATO, Adair M.; GOMES, Adriana A. Molina; GRANDO, Regina Célia. Experiências com geometria na escola básica: narrativas de professores em (trans)formação. São Carlos: Pedro \& João Editores, 2008.

OLIVEIRA, Marta Kohl de. Vygotsky: aprendizado e desenvolvimento: um processo sócio histórico. São Paulo: Scipione, 1997. (Pensamento e ação no magistério).

PIMENTA, Selma Garrido. Professor reflexivo: construindo uma crítica. In: PIMENTA, Selma Garrido; GHEDIN, Evandro. (Org.). Professor reflexivo no Brasil: gênese e crítica de um conceito. São Paulo: Cortez, 2002. p. 17-52.

PONTE, J. P.; BOAVIDA, A. M.; GRAÇA, M.; ABRANTES, P. Didáctica da Matemática. Lisboa: Ministério da Educação. Departamento do Ensino Secundário, 1997.

PONTE, João Pedro. Investigar a nossa prática. GTI - Grupo de Trabalho e Investigação. Reflectir e investigar sobre a prática profissional. Portugal: Associação de professores de Matemática, 2002. p. 5-55.

PONTE, João Pedro; BROCADO, Joana; OLIVEIRA, Hélia. Investigações matemáticas na sala de aula. Belo Horizonte: Autêntica, 2003.

ROGOFF, Bárbara. Observando a atividade sociocultural em três planos: apropriação participatória, participação guiada e aprendizado. In: WERTSH, James V.; RIO, Pablo del; ALVAREZ, Amélia. Estudos socioculturais da mente. Trad. Maria da Graça Gomes Paiva e André Rossano Teixeira Camargo. Porto Alegre: ArtMed, 1998. p. 123-142.

SMOLKA, A.L.B.; NOGUEIRA, A. L.H. O desenvolvimento cultural da criança: mediação, dialogia e (inter) regulação. In: OLIVEIRA, M. K.; SOUZA, D.T.; REGO, T. 
C. (Org.). Psicologia, Educação e as temáticas da vida contemporânea. São Paulo: Moderna, 2002. p. 77-94.

TUDELLA, A. et al. Dinâmica de uma aula com investigações. In: ABRANTES P.; PONTE, J.P.; FONSECA, H. e BRUNHEIRA, L. (Org.). Investigações matemáticas na aula e no currículo. Lisboa: Projeto MPT e APM, 1999. p. 87-96.

ZEICHNER, Kenneth M., DINIZ-PEREIRA, Júlio E. Pesquisa dos educadores e formação docente voltada para a transformação social. Cadernos de pesquisa, São Paulo, v. 35 , n. 125, p. 63-80, maio/ago. 2005.

\section{NOTAS}

${ }^{1}$ Apoio Financeiro: FUNDESP

${ }^{2}$ Não temos preocupação, neste texto, em estabelecer diferença entre saber e conhecimento; os termos serão usados indistintamente.

${ }^{3}$ No diálogo, a sigla "P" refere-se à professora; as siglas "A1, A2, A3 e A4", aos alunos. É importante destacar que, durante a audiogravação, o gravador sempre ficava em um dos grupos (com três ou quatro alunos) de trabalho na sala de aula.

${ }^{4}$ A tarefa foi realizada no dia 28/4/2005 e a gravação corresponde a um grupo com três componentes, em uma turma do $1^{\circ}$ ano do ensino médio, com 36 alunos frequentes.

${ }^{5}$ Tarefa realizada no dia 1/6/2005; a gravação corresponde a um grupo de quatro alunos, de uma turma com 36 alunos frequentes.

${ }^{6}$ A professora induzia-os a usar representações do tipo: $4=2 \times 2$ e $9=3 \times 3$.

Recebido: 25/01/2007

Aprovado: 05/02/2009

Contato:

Programa de Pós-Graduação Stricto Sensu em Educação Universidade São Francisco Rua Alexandre Rodrigues Barbosa, 45 - Centro Itatiba - SP CEP 13251-040 